Canadian Studies in Population, Vol. 16 (1), 1989, pp. 1-24

\title{
DEMOGRAPHIC TRENDS, LIFE COURSE, AND FAMILY CYCLE - THE CANADIAN EXAMPLE: Part I. Changing Longevity, Parenting, and Kin-Availability
}

\author{
Judah Matras \\ Carleton University, Ottawa, Ontario, Canada and \\ Brookdale Institute of Gerontology, Jerusalem, Israel
}

Résumé - Une bonne partie de la vie personnelle et sociale est organisée par le cours de vie individuelle et le cycle de vie familiale, ses paramètres, son minutage des transitions et sa mobilité parmi et en dedans des domaines d'activité, et les réactions du cours de vie et du cycle de vie aux tendances démographiques sont le méchanisme principal par lequel la vie sociale et personnelle réagit aux changements démographiques, technologiques et d'informations modernes. Au Canada comme ailleurs, la structure même du cours de vie est affectée par les changements démographiques, et particulièrement durant la période moderne du vieillissement des populations: par la longévité prolongée, la paternité diminuée et les plus petits réseaux de parenté à travers tout le cours de vie. Les changements dans le cours de vie, tour à tour, impliquent de nouveaux types de dépendance et d'obligation engendrant de nouveaux besoins et d'exigences pour les services publics et sociaux et, peut-être bien, de nouvelles ressources privées et familiales pour les aborder aussi bien que des changements dans les types de participation en production, en consommation, en relations communautaires, et en activité sociale et économique en général: 
Abstract - Much of personal and social life is organized by the individual life course and family life cycle, its parameters, timing of transitions, and mobility among and within activity domains; and life course and life cycle responses to demographic trends are the main mechanism by which social and personal life respond to modern demographic, technological, and informational changes. In Canada, as elsewhere, life course structure itself is affected by demographic changes, especially in the modern period of the aging of populations: by extended longevity, diminished parenting, and smaller kinship networks through most of the life course. In turn, changes in the life course imply new patterns of dependency and obligations engendering new needs and demands for public and social services and, possibly, new private and familial resources for addressing them, as well as changes in patterns of participation in production, consumption, community relations, and social and economic activity in general.

\section{Key Words - mortality, fertility, life course, family cycle, aging}

\section{Introduction: Demographic Transitions, the Life Course, and Socioeconomic Structure}

Canada's population is an aging one. Low mortality, low or declining fertility, and the aging of populations imply not only that more people are living longer and that there are more elderly persons in the population, but it also signals a new framework for organization of the individual life course and a new framework for family and community interdependence and relationships. In particular, the age-related patterns of dependency, of family and social obligations, and of entitlements and claims on family and community are affected and undergo change due to the changing demographic, socioeconomic and political contingencies of individual and population aging.

The demographic transitions from the "high balance" regime of high fertility offset by high mortality to the "low balance" regime of low fertility and low mortality first engender a dependency "crunch." In twentieth century societies, this has given rise to demands for social or political (typically government) intervention and welfare measures to diminish the hardships and inequities of the new dependency. The completion or maturing of the demographic transitions subsequently engenders liberation from dependency through (i) controlled fertility, (ii) women's employment outside the home and (iii) public assumption of risks and schemes for maintenance of income, services, and consumption. That these trends have been occurring conjointly with dramatic technological developments and revolutionary changes in production, storage, and access to 
knowledge and information has rendered them even more compelling in their impact on individuals, families, communities, national societies, and the world social, economic and political community. This paper, Part I, reviews the bearing of recent demographic trends on longevity, parenting and kinavailability in the life course. A companion paper, Part II, considers trends in employment, parenting and their alternatives in the life course (Matras, 1990).

Societies and social organizations generally, and social inequality and stratification regimes in particular, are subject to a variety of discontinuities and disequilibria arising from population turnover and cohort flows and succession. The extent and manner in which stability and continuity - or "reproduction of social relations" - are affected, or in which change is introduced, are dependent in large measure upon the social structuring and organization of the life course, that is, of the physiological, psychological, and social process and sequence of capacities and age-graded or time- and duration-dependent events, activities, and relationships characterizing the individual from birth through death. This point has been made in a variety of formulations and in a variety of disciplinary contexts. The concepts of socialization, career, intergenerational mobility, class- or strata-culture, life transitions, seniority, rites de passage, inheritance and social reproduction all concern and address aspects of individual and aggregate life course patterns of social organization.

\section{Concept of the Life Course}

The life course refers to pathways through the age-differentiated life span, to social patterns in the timing, duration, spacing and order of events. The timing of an event may be as consequential for life experience as whether the event occurs and the degree or type of change. Age differentiation is manifested in expectations and options that impinge on decision processes and the course of events that give shape to life stages, transitions and turning points. Such differentiation is based in part on the social meanings of age and the biological facts of birth, sexual maturity and death. These meanings have varied through social history and across cultures at any point in time, as documented by evidence on socially recognized age categories, grades and classes.

Thus the "life course" refers to the trajectory of sociodemographic states (that is statuses and roles) through which members of a birth cohort pass during their lifetimes. This time-path can be highly individualistic or it can be normative (typical). The degree to which it is normative can vary by chronological age and/or across the experience of successive cohorts. The life course of an individual is his or her biography cast in terms of characteristic and socially- 
relevant activity, events, processes, and durations. The life course of a cohort is the distribution of that cohort across time over the spheres or domains of activity and over characteristic events, event sequences or processes.

\section{Age Roles and Age Grading}

A central concept in the description and analysis of the life course is the "age role," a social role associated with a given chronological age. The concept of "age grading" in society refers to the association of social roles with chronological age, for example, the association of school entrance, marriage, citizenship obligations or entitlements with given chronological ages. Age grading tends to impose social norms about the expected behaviour, activity and relationships at the ages in question and, for the succession of age-graded roles, for the life course generally. Even elementary age classes which we recognize today infancy, childhood, adolescence, adulthood, middle-age and old-age - were either not identified at all in the past or were identified and characterized in different ways and in different relationships to chronological age and to one another than is the case today. One of the central hypotheses of the research on the life course is that there is an historical trend toward increasing age-grading in complex societies both with regard to the numbers of activities and activity domains which are age-graded and to the detail with which they are differentiated by age. Age grading is more detailed, more complex, year-by-year rather than category-by-category; and there are many more age-grades per decade and per lifetime. Age grading is more differentiated, with different patterns, clocks, timing, durations for the separate social spheres or domains the more highly differentiated social and economic life and relationships (Elder, 1975; Featherman, 1985; Hareven, 1982a; Mayer and Muller, 1987).

In Canada, as in other advanced, secular, private-market, industrial societies, three major trends influence the life course, indeed partly revolutionize it. Through their effects on the life course of individuals and successive cohorts, they also affect the processes of status attainment, mobility and strata formation, as well as the basic axes of social organization, legitimacy and order and the well-being and life chances of individuals and families. These three major trends and processes are:

1. The changing demographic regime, in the direction of declining mortality and increased longevity and joint survival of couples, families or other social units, of declining fertility, smaller families, sibships, and kinship units, and of compressed or more compact childrearing time budget. 
2. The changing technologies leading to expanded production of goods and services, accompanied by diminishing and partially redundant employment and by the growth of non-employment-based income entitlements.

3. The revolutions in information and communications and the enhanced transparency, or mutual visibility, among the various social strata leading to diminishing acceptability of social inequalities of opportunity and condition. These have frequently led to demands and expectations of income transfer schemes and more explicit politicization of income distribution.

A number of very important consequences follow from these processes. Expressed very cryptically, these are:

1. Parenting and demographic viability: Societies can and do survive and flourish without universal parenting and with only short-term and less intensive parenting required on the part of those becoming parents. More than any other factor, diminished fertility has changed the content, structure and timing features of the individual life course and family cycle, as well as the life course pattern of kinship presence, dependencies and obligations.

2. Work and material welfare: Societies and their individual members can enjoy minimal, and perhaps reasonably high, levels of material welfare and security with short-term and less intensive lifetime employment. Employment remains the central mechanism for allocation of income and the goods and services it buys. Various extra-employment income maintenance measures operate both to assure income to those without employment-based entitlements and to regulate the demand for employment. However, there remains deep competition and struggle over employment reflected in the various bounds, constraints and organizational features of the labour market.

3. Visibility, knowledge, and demand: Many individuals and groups in modern societies already enjoy the advantages and possibilities of items 1 and 2 above, and increasingly more people, organized groups and social strata are becoming aware of them and are demanding them from their elites, leaders or governments.

4. Age-grading and age-roles: Due to the new relationships between the life span and new demographic and economic realities, many of the traditional patterns of age-grading, of age-related allocation of roles, and of age-related rules and expectations regarding schooling, family functions, employment and leisure are anachronistic in contemporary societies. 


\section{Extended Longevity and the Composition of Life Years}

Some important features of the patterns of declining mortality in Canada and their implications for the life course of individuals and life cycle of families are presented in Table 1, and in Appendix Table A showing stationary populations (or: life years lived in successive age intervals) of male and female life tables for Canada in 1921, 1951, and 1981. These are taken from the set of historical abridged life tables recently prepared by D. Nagnur and published by Statistics Canada (Nagnur, 1986). The latter are synthetic or cross-sectional life tables, rather than true historical life tables, and they must be interpreted in terms of hypothetical cohorts subject throughout their lives to the mortality conditions observed in the year in question: 1921, 1951 or 1981.

This is precisely the point of view which we are adopting in order to consider the implications of mortality changes for the life course of individuals and of cohorts born at successive time points. Thus, a male cohort of 100,000 individuals born at the same time and subject to the mortality conditions observed in 1921 (actually in the years 1920-1922) would live a total of 5,884,297 life years until all would be dead, or an average of 58.8 years (the life expectancy at birth implied by those mortality conditions). But a male cohort subject to the mortality conditions of 1981 (again, actually of the years 1980-1982) would live a total of 7,187,867 life years or an average of 71.9 years (the life expectancy at birth associated with the 1981 mortality conditions). There was an increase of some 22 per cent in the number of life years lived by the male cohort subject to 1981 mortality levels compared to that for males subject to 1921 mortality levels. Even more dramatic: female cohorts subject to the 1981 mortality rates would enjoy greater than 30 per cent more life years than those subject to 1921 mortality.

As we note in Table 1 (and in even more detail in Appendix Table A), beyond the differences between improvements in male and female longevity and life years, which we have already noted above, the increments to the volume of life years did not take place uniformly over the period examined, 1921-1981, nor were they uniform among the age levels. For males and females alike, the increments to the volume of life years lived were much more pronounced and dramatic in the first half of the period, 1921-1951 (column 2 of Table 1), than in the second half, 1951-1981 (column 3 of Table 1). For males, the number of life years lived by the hypothetical cohort increased by almost 13 per cent in the early part, compared to an eight per cent increase in total life years achieved in the later part of the 1921-1981 period; and for females, the increase was 17 per cent in 1921-1951, compared to an eleven per cent increment in 1951-1981. 
Longevity, Parenting, and Kin-Availability

\begin{abstract}
TABLE 1. LIFE TABLE LIFE YEARS (LX) IN SELECTED AGE INTERVALS, BY SEX. CANADA: 1920-22, 1950-52 AND 1980-82
\end{abstract}

\begin{tabular}{|c|c|c|c|c|c|c|}
\hline & Life & ars Lived & & of Chang & $1920-22$ & $1980-82$ \\
\hline AGE & $1920-2$ & $1950-2$ & $1980-2$ & $1921-81$ & $1921-51$ & $1951-81$ \\
\hline -Males & & & & & & \\
\hline Total & 5884297 & 6640474 & 7187867 & 22.2 & 12.8 & 8.2 \\
\hline $\begin{array}{l}<20 \\
20-60 \\
60-75 \\
75+ \\
-\frac{8}{8} \quad \mathrm{Di}\end{array}$ & $\begin{array}{r}1745343 \\
3081732 \\
782971 \\
274251 \\
t:-\end{array}$ & $\begin{array}{r}1892677 \\
3518959 \\
898875 \\
329963\end{array}$ & $\begin{array}{r}1969819 \\
3734835 \\
1029115 \\
454098\end{array}$ & $\begin{array}{l}12.8 \\
21.2 \\
31.4 \\
65.6\end{array}$ & $\begin{array}{r}8.4 \\
14.2 \\
14.8 \\
20.3\end{array}$ & $\begin{array}{r}4.1 \\
6.3 \\
14.5 \\
37.6\end{array}$ \\
\hline Total & 100.0 & 100.0 & 100.0 & 100.0 & 100.0 & 100.0 \\
\hline $\begin{array}{l}<20 \\
20-60 \\
60-75 \\
75+ \\
-\end{array}$ & $\begin{array}{r}29.7 \\
52.4 \\
13.3 \\
4.7\end{array}$ & $\begin{array}{r}28.5 \\
53.0 \\
13.5 \\
5.0\end{array}$ & $\begin{array}{r}27.4 \\
52.0 \\
14.3 \\
6.3\end{array}$ & $\begin{array}{l}17.2 \\
50.1 \\
18.9 \\
13.6\end{array}$ & $\begin{array}{r}19.5 \\
57.8 \\
15.3 \\
7.4\end{array}$ & $\begin{array}{l}14.1 \\
39.4 \\
23.8 \\
22.7\end{array}$ \\
\hline Femal & $:-$ & & & & & \\
\hline Total & 6060369 & 7090403 & 7905888 & 30.4 & 17.0 & 11.5 \\
\hline $\begin{array}{l}<20 \\
20-60 \\
60-75 \\
75+ \\
-\frac{9}{6} \text { Dis }\end{array}$ & $\begin{array}{r}1789008 \\
3148375 \\
814112 \\
308874\end{array}$ & $\begin{array}{r}1915157 \\
3647144 \\
1054911 \\
473191\end{array}$ & $\begin{array}{r}1977637 \\
3855584 \\
1234864 \\
837803\end{array}$ & $\begin{array}{r}10.5 \\
22.5 \\
51.7 \\
171.2\end{array}$ & $\begin{array}{r}7.0 \\
15.8 \\
29.6 \\
53.2\end{array}$ & $\begin{array}{r}3.3 \\
5.7 \\
17.1 \\
77.0\end{array}$ \\
\hline Total & 100.0 & 100.0 & 100.0 & 100.0 & 100.0 & 100.0 \\
\hline $\begin{array}{l}<20 \\
20-60 \\
60-75 \\
75+\end{array}$ & $\begin{array}{r}29.5 \\
52.0 \\
13.4 \\
5.1\end{array}$ & $\begin{array}{r}27.0 \\
51.4 \\
14.9 \\
6.7\end{array}$ & $\begin{array}{l}25.0 \\
48.8 \\
15.6 \\
10.6\end{array}$ & $\begin{array}{l}10.2 \\
38.3 \\
22.8 \\
28.7\end{array}$ & $\begin{array}{l}12.2 \\
48.4 \\
23.4 \\
16.0\end{array}$ & $\begin{array}{r}7.7 \\
25.6 \\
22.1 \\
44.7\end{array}$ \\
\hline
\end{tabular}

Source: Appendix, Table A

Throughout the period 1921-1981, the relative increments in life years lived at older ages, say at 60 and over, are greater than those in numbers of life years lived in youth and adulthood, say at ages under 20 or at ages $20-60$, with the relative increase in life years lived at ages 75 and over especially pronounced. Yet in the first half of the period, 1921-1951, the larger part of the increase in life years lived -77 per cent of the increment for males and 61 per cent of the increment for females - was accounted for by increases in life years lived at ages under 20 or at working ages, $20-60$ (see column 5 in Table 1). However, in the later half of the period 1951-1981, almost two-thirds (63 per cent) of the 
increment in life years for females, and just under half ( 47 per cent) of the increment in life years for males, were additions to years of life lived at ages 60 or over (column 6 of Table 1). Thus the changes in mortality occurring in the 1921-1951 portion of the period added very substantially to the volume of life years which were potentially "working years of life," that is, at ages 20-60. The changes in the 1951-1981 portion (sometimes denoted as "rectangularization of the survival function" because the proportion surviving to the oldest ages increases while the "maximum" life span is essentially unchanged) continued to add substantially to the volume of life years at the "working ages," $20-60$, but at the same time they have also added substantially to the volume of life years at late middle and old age, 60 or over.

For male cohorts surviving and dying in accordance with the mortality conditions of, respectively, 1921, 1951 and 1981, there are substantial increments to the total volumes of life years, but the percentages of the total life years lived in each of the respective age categories do not change much. However for female cohorts, there is a notable decrease in the percentage of life years lived at ages under 20 and also in the ages 20-60, while the percentage of life years lived at ages 60-75 and at ages 75 or more increased notably under the mortality conditions of 1981 compared to those of the earlier years.

\section{The Compression and Partial Redundance of Parenting}

The historical long-term decline of fertility in Canada and elsewhere in the West is well-known, and the association of smaller families and employment of women in the organized labour market with declining fertility is also widely recognized. Yet the implications of these trends for the organization of the individual life course of women, and for the lifecycles of families, are only vaguely understood. In particular, the specific causal connections between childbearing and childrearing trends and alternative life course activities (for example, schooling, employment, parent- or other care activities) remain obscure. The external factors (for example, social class or socioeconomic status, family income, job market factors, husband's or partner's activities, career or family orientations, educational attainment or vocational training, work experience and mothers' employment histories) bearing on these connections have been extremely difficult to sort out (see Davis, 1984; and the review paper by Lehrer and Nerlove, 1986).

An important link between the recent trends in mortality and fertility and the entire range of personal and socioeconomic activities and relationships is that which derives from the compression and compacting of parenting in the life 
course of adults and of adult women especially, that is, the diminishing intensity and reduced durations of parenting even as the numbers of life years have expanded. Unfortunately there is no straightforward measure or indicator of "parenting" readily available in census, survey or vital statistics data. Such data usually refer to "births:" births in a given calendar year, births to women (or sometimes, fatherhood among men) of given ages, or children-ever-born to women of given ages or characteristics. Obviously mothers and fathers parent for years after the births of their children, and they may do so with respect to several children simultaneously.

Data on families or on households (allowing couples or persons to be identified according as they do or do not have dependent children residing with them) may be satisfactory indicators of parenting, provided they are available in sufficient sex and age detail for the parents or heads of households. However, such data inherently relate parenting and rates and durations of parenting to family heads or to heads of households, and they require adjustments for relating them to the general population.

An example of such an analysis of the allocation of early adult life-years (between ages 18 and 29) among schooling, employment and parent-hood has been carried out for the United States in the 1960-1976 period by J. Sweet (1979a, 1979b, 1979c). Under 1976 conditions, White American women would be childless an average of 7.10 years during the age period in question. However, this varies sharply by educational attainment: for women with less than 12 years of schooling, about 16 per cent of ever-married life-years at ages 18 and 29 are years without own children in their households. But women with 12 years of schooling would spend 30 per cent, and those with more than 12 years of schooling would spend 48 per cent, of the 18-29 age period without children (Sweet, 1979c, Tables 12, 14).

Some panel or longitudinal data obtained in specialized surveys yield information on parenting. In particular, the Family History Survey and the General Social Survey carried out recently by Statistics Canada include information on extent, intensity and durations of parenting of respondents, but analyses of these data have not yet been extensively published.

Age-specific fertility rates for Canadian women in 1871, 1891, 1921, 1951, 1961 and 1981 are shown in Table 2. These data reflect clearly the decline of fertility in the first part of this century, some recovery (the "baby boom") in the years following World War II, and the steep decline in the most recent decades. They reflect also the near-disappearance of fertility at the later ages of fecundability, say at ages over 35 , a trend which continued even during the years of the "baby boom." Although earlier marriage in the 1940s and 1950s contributed to the decline in the mean age at fertility, the most important and most consistent 


\section{Judah Matras}

element in the decline in age at fertility has been the reduction of fertility in the older ages.

TABLE 2. AGE - SPECIFIC FERTILITY RATES (PER 1000) AND TOTAL FERTILITY RATE (PER WOMAN), CANADA: 1871-1981

\begin{tabular}{|c|c|c|c|c|c|c|c|}
\hline AGE & 1871 & 1891 & 1921 & 1941 & 1951 & 1961 & 1981 \\
\hline $\begin{array}{l}15-19 \\
20-24 \\
25-29 \\
30-34 \\
35-39 \\
40-44 \\
45-49\end{array}$ & $\begin{array}{r}37 \\
174 \\
310 \\
353 \\
320 \\
152 \\
20\end{array}$ & $\begin{array}{r}23 \\
165 \\
274 \\
249 \\
179 \\
83 \\
11\end{array}$ & $\begin{array}{r}38.0 \\
165.4 \\
186.0 \\
154.6 \\
110.0 \\
46.7 \\
6.6\end{array}$ & $\begin{array}{r}30.7 \\
138.4 \\
159.8 \\
122.3 \\
80.0 \\
31.6 \\
3.7\end{array}$ & $\begin{array}{r}48.1 \\
188.7 \\
198.8 \\
144.5 \\
86.5 \\
30.9 \\
3.1\end{array}$ & $\begin{array}{r}58.2 \\
233.6 \\
219.2 \\
144.9 \\
81.1 \\
28.5 \\
2.4\end{array}$ & $\begin{array}{r}25.9 \\
94.7 \\
124.2 \\
66.6 \\
19.0 \\
3.1 \\
0.2\end{array}$ \\
\hline $\begin{array}{l}\text { Total } \\
\text { Fertil } \\
\text { Rate }\end{array}$ & 6.83 & 4.92 & 3.53 & 2.83 & 3.50 & 3.84 & 1.6 \\
\hline
\end{tabular}

TABLE 3. ESTIMATES OF FEMALE LIFE YEARS IN PARENTING, BY AGE, CANADA: 1921, 1951, AND 1981

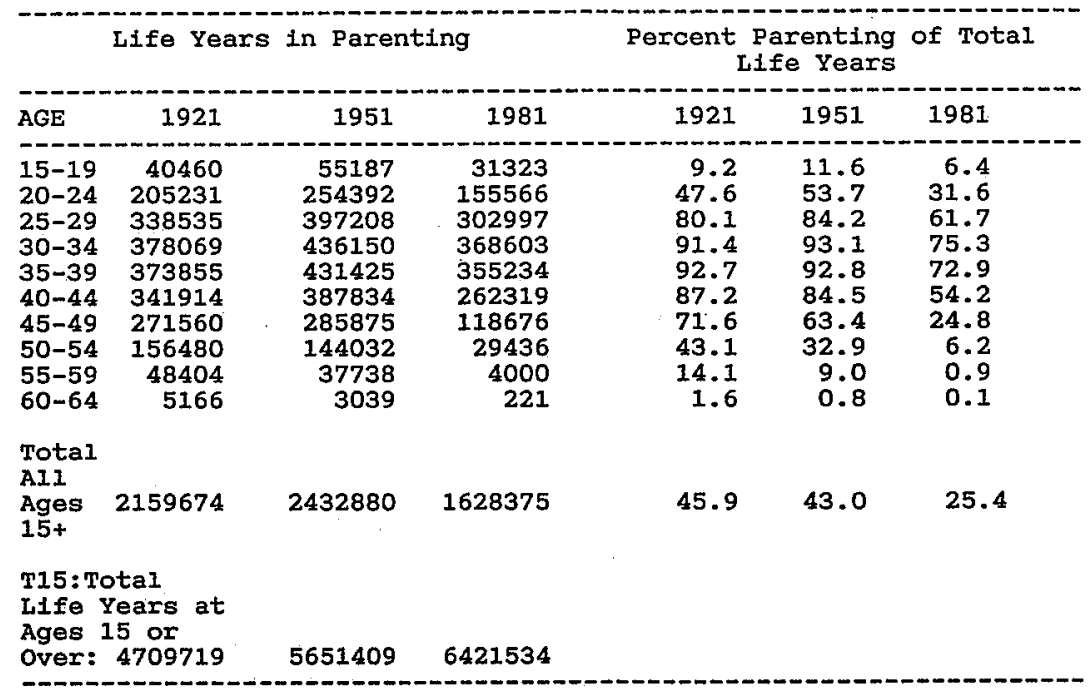

Source: Appendix Table $A$ and Table 2. See Text for computation procedure. 
A crude but illustrative measure of life years of parenting is presented in Table 3. For each age group this measure, $L p(x)$, is calculated as the product of the stationary population, $L(x)$, and an estimate, $\operatorname{Par}(x)$, of the probability of being a parent at that age. 1

Measures of the life years in parenting for women at each age level are shown in Table 3, based on the female stationary populations and on the fertility schedules for each of the years 1921, 1951 and 1981. The left panel shows life years in parenting while the right panel shows the percentage in parenting of the total life years lived at each age. A cohort of 1,000 females subject to the mortality conditions and fertility rates observed in Canada in 1921 would live a total of $4,709,700$ life years at ages 15 or over, of which $2,159,700$, or 46 per cent, would be years spent parenting one or more children under the age of 15 . About nine per cent of life years at ages 20-24 would be taken up with parenting for such a cohort, but by ages 35-39 this would rise to almost 93 per cent of life years at ages 35-39. At ages 40-44 about 87 per cent, and at ages $45-49$ just under three-quarters, of life years for such a cohort would be taken up with parenting.

Under mortality and fertility conditions observed in 1981, a cohort would live a total of $6,421,500$ years at ages 15 or over, but only $1,628,400$ life years, or just 25 per cent, would be devoted to parenting. In such a cohort, about three-quarters of the total life years lived at ages 30-34, and just less than 73 per cent at ages 35-39 (normally the peak parenting ages), would be devoted to parenting.

\section{Kinship and Kin-Dependency, Obligations and Entitlements Across the Life Course}

Although demography of the family has enjoyed much attention recently (Watkins et al., 1987), progress in linking the major demographic trends to family structure and to the behaviour of individuals in the context of family membership has been slow (Davis and van den Oever, 1982; Hagestad, 1986). There have, however, been a number of attempts to relate important categories of behaviour, for example, leaving parental homes or formation of independent households (Goldscheider and DaVanzo, 1986; Kobrin, 1980), women's entrance into the labour force (Oppenheimer, 1982), and changing residence (Rossi, 1955), to individual life course or family life cycle stages or transitions. Also, some researchers have advanced some important hypotheses concerning shifts in patterns of intrafamily dependency, transfers and support as related to the changing size, structure and longevity of families (Modell et al., 1976). 


\section{Survival of Kin}

An important contribution to relating demographic variables, such as the mortality and fertility schedules, to family structure is developing in the work of Keyfitz and his collaborators and followers on the demography of kinship (Bongaarts et al., 1987; Goodman et al., 1974; Keyfitz, 1985, 1986). They have developed procedures for estimating, in the stable populations generated by mortality and fertility regimes, the probabilities of survival of kin, for example, parent, sibling, child, or of the number of kin born and surviving at each age of an individual in such a population. Thus, for example, under the mortality and fertility conditions of Canada in 1971 (that is, in the stable population which would be generated by the indefinite continuation of the mortality and fertility rates observed in Canada in 1971), for a woman reaching age 20 the probability of having a mother still alive is 0.967 ; and for a woman in such a population reaching age 60 , the probability of having a mother still alive is 0.322 . However, under the 1981 Canadian and fertility conditions, the corresponding probabilities are 0.983 and 0.396 , respectively. Under the lower mortality conditions of 1981, an individual woman herself reaching age 60 years of age is considerably more likely to have her mother still surviving and alive than would be the case under the 1971 mortality regime (Keyfitz, 1986: Table 2).

Taking as an example the numbers of daughters born and the numbers surviving under the 1971 and the 1981 demographic regimes respectively, Keyfitz calculated that, under 1971 conditions, for women themselves surviving and reaching age 60 the expected number of daughters ever born would be 1.036 and the expected number still alive (when mothers reach 60 ) is 1.001. However, under the 1981 conditions the expected number born would be only 0.813 while the expected number surviving and still alive when the women reach 60 years of age is 0.797. In this instance, the main factor in the change from the 1971 to 1981 demographic conditions is the decline in fertility, which overrides by far the effect of the mortality decline in the same period.

That the life course kinship network shifts in time, say over successive cohorts or generations, in accordance with changing mortality and fertility is suggested in the comparative calculations first presented by Goodman et al., (1974) for the United States, Venezuela and Madagascar and by Keyfitz (1986) for Canada alone in the 1971 and 1981 comparisons. More dramatic examples of the rapid shifts in life course kinship networks implied by steep mortality and fertility inflections have been derived by A. Shmueli (1985) for subpopulations in Israel, such as Jews of Asian or African birth or origins and Moslems, both with recent histories of greatly diminishing mortality and even more recent beginnings of fertility decline. For example, the expected number of daughters of non-Jewish 
women in Israel subject to the 1960 demographic regime born and born-andstill-alive at age 45 was estimated by Shmueli as 3.514 daughters per woman (the Moslem total fertility rate in 1960 was 9.31); but for those subject to the 1980 demographic regime, the expected number of daughters born and still alive at age 45 was down to 2.748 (total fertility rate for Moslem women was down to 5.98 in 1980). The expected number of living sisters a non-Jewish woman aged 65 would have had under the demographic regime of 1960 was 2.47 , while the corresponding figure under the 1980 demographic regime was 1.94. Finally, the probability that a non-Jewish woman reaching age 60 still had a living mother was 0.2093 under the 1960 demographic regime, while under the fertility and mortality conditions of 1980 the corresponding probability reached 0.3025 , an increase close to 50 per cent (Shmueli, 1985: Table 18).

More generally, Keyfitz and his associates have shown that while Western populations have experienced both declining mortality and declining fertility, the outcomes with respect to the "availability" of kin at each age differ for parents and for other kin. With respect to the survival of parents: each person in a population has only one pair of natural parents, and declining mortality enhances the chance of having a surviving parent at each age (though these are not entirely indifferent to fertility variations: the earlier in his parents' lifetime that an individual is bom, the greater the chance of the parents' survival to any given age of the individual). However with respect to the numbers and survival of siblings, children, and second- or higher-order kin: declining fertility tends to override declines in mortality and reduces the numbers of all kin, even as each one born is likely to survive longer. Thus, the present generation of adult parents has, to be sure, fewer children making claims on time, attention and resources than had earlier generations. However, as elderly couples or individuals, they will also have fewer surviving children and grandchildren improved mortality notwithstanding - to entertain or care for them in old age.

\section{Joint Survival of Spouses}

Unfortunately, these stable population models and calculations have not yet dealt in detail with a most important kin relationship: that between husbands and wives. Though we have estimates of the probabilities of survival of parents and of the expected numbers of other first- and second-order kin, at each age of individuals in stable populations under varying mortality and fertility regimes, we do not have probabilities of survival of spouses. This is probably because derivation of such probabilities is particularly complex and involves two-sex population models, all combinations of ages-at-marriage and of age differences 
between grooms and brides, and assumptions about the mutual dependency or independence of mortality of partners in marriages (see Feichtinger, 1987).

However, it is again possible to make some crude but suggestive calculations of probabilities of joint survival of couples, using the data initially presented showing changes in the volumes and age composition of life years of cohorts subject to the mortality conditions of 1921, 1951 and 1981 respectively (Appendix Table A). Such calculations are shown in Table 4 for couples with three separate combinations of age-at-marriage and age differences between groom and bride. "Joint survival" is taken to mean, simply, both members of the couple staying alive, but this can occur with the marriage intact or otherwise; at this point no information is used or introduced on stability or dissolution - other than by death of one spouse.

For each such combination, probabilities of joint survival for 20 years, 30 years, 40 years and 50 years are estimated as products of life table survival probabilities, $L(x+t) / L(x)$, for grooms and brides of the respective ages, $x$, with the length of the period, $t$, taken successively as 20,30 and 40 years.

For each type of couple (where each type reflects some combination of ages-at-marriage and age differences between groom and bride), the probabilities of joint survival for 20 years after marriage are notably higher for couples subject to 1951 mortality than for those subject to 1921 mortality. They are even higher for those subject to 1981 mortality. Indeed the changes are fairly substantial, especially in the earlier part of the period, 1921-1951. The probabilities of joint survival for longer periods - 30,40 and 50 years - vary even more sharply and dramatically and are very substantially higher for those subject to the successively later, 1951 and 1981 , mortality regimes.

It is the survival rates of the women which underwent the greatest increase betwen 1921 and 1951, with the rates for the men improving only modestly (Table 4). However, survival rates for both men and women improved notably in the interval from 1951 to 1981 , except at the young adult ages, where they improved to a much lesser extent. Thus, for a bride and groom both 25 years old, marrying in 1921, and subject thereafter to the mortality conditions of 1921, the probability that both would survive another 30 years and reach age 55 was 0.6609; but for the couple both aged 25, marrying in 1981, and subject thereafter to the mortality conditions of the year 1981 , the probability that both would survive 30 years and reach age 55 was 0.8278 , representing an improvement in this joint survival probability amounting to approximately 25 per cent. For the same type of couple, the probability of surviving 40 years after marriage improved by 44 per cent (from 0.4223 under 1921 mortality rates to 0.6100 under 1981 mortality conditions), and the probability of surviving 50 years after marriage improved by 118 per cent (from 0.1331 to 0.2903 ). 


\section{TABLE 4. ESTIMATED PROBABILITIES OF JOINT SURVIVAL OF HUSBANDS AND WIVES MARRYING AT SELECTED AGES, CANADA: 1921, 1951, AND 1981}

\begin{tabular}{|c|c|c|c|c|}
\hline \multirow{2}{*}{$\begin{array}{l}\text { Year and Ages at } \\
\text { Marriage }\end{array}$} & \multicolumn{4}{|c|}{ Survival } \\
\hline & 20 years & 30 years & 40 years & 50 years \\
\hline \multicolumn{5}{|l|}{$-1921:-$} \\
\hline Groom Aged 25 & .9073 & .8164 & .6464 & .3548 \\
\hline Bride Aged 20 & .9089 & .8421 & .7303 & .5167 \\
\hline Joint Survival & .8247 & .6875 & .4720 & .1833 \\
\hline Groom Aged 25 & .9073 & .8164 & .6464 & .3548 \\
\hline Bride Aged 25 & .8971 & .8096 & .6533 & .3750 \\
\hline Joint Survival & .8139 & .6609 & .4223 & .1331 \\
\hline Groom Aged 30 & .8863 & .7578 & .5234 & .2057 \\
\hline Bride Aged 25 & .8971 & .8096 & .6533 & .3750 \\
\hline Joint Survival & .7951 & .6135 & .3419 & .0771 \\
\hline$-1951:-$ & & & & \\
\hline Groom Aged 25 & .9397 & .8444 & .6578 & .3740 \\
\hline Bride Aged 20 & .9679 & .9243 & .8324 & .6398 \\
\hline Joint Survival & .9096 & .8173 & .5476 & .2392 \\
\hline Groom Aged 25 & .9397 & .8444 & .6578 & .3740 \\
\hline Bride Aged 25 & .9549 & .8920 & .7568 & .4885 \\
\hline Joint Survival & .8973 & .7532 & .4978 & .1827 \\
\hline Groom Aged 30 & .9101 & .7703 & .5328 & .2190 \\
\hline Bride Aged 25 & .9549 & .8920 & .7568 & .4885 \\
\hline Joint Survival & .8690 & .6872 & .4032 & .1070 \\
\hline$-1981-$ & & & & \\
\hline Groom Aged 25 & .9576 & .8839 & .7203 & .4426 \\
\hline Bride Aged 20 & .9843 & .9585 & .8982 & .7663 \\
\hline Joint Survival & .9426 & .8472 & .6470 & .3392 \\
\hline Groom Aged 25 & .9576 & .8839 & .7203 & .4426 \\
\hline Bride Aged 25 & .9767 & .9366 & .8468 & .6559 \\
\hline Joint Survival & .9354 & .8278 & .6100 & .2903 \\
\hline Groom Aged 30 & .9353 & .8217 & .5980 & .2847 \\
\hline Bride Aged 25 & .9767 & .9366 & .8468 & .6559 \\
\hline Joint Survival & .9135 & .7696 & .5064 & .1867 \\
\hline
\end{tabular}

Source: Appendix Table A. See text for computation procedures.

\section{Discussion}

There were large gains in longevity in the 1921-1951 portion and somewhat more modest gains in the 1951-1981 portion of the 1921-1981 period. In the earlier part of the period, the gains were concentrated in the adult ages, 20-60, and may be said to have yielded additional life years at ages traditionally 
characterized by employment, parenting, and adult and middle-age activity for cohorts experiencing those mortality patterns. In the latter part of the period, the gains were more concentrated in the later years, 60-75 and 75 and over and especially dramatic for females at ages 75 and over. These later gains in longevity may be said to have yielded additional life years at ages characterized by post-employment and post-parenting activity for the cohorts.

Younger cohorts have experienced substantially reduced mortality and considerably larger numbers of total life years. However, both the absolute numbers of life years and the percentages of life years lived at each age that are taken up with parenting are very much smaller. Obviously, it is the percentages of total life years at each age not taken up with parenting that are of special interest. The activities, relationships and social arrangements, and the material entitlements and sources of social status which replace the involvement in parenting will be considered in Part II. At this point it suffices to note that, under the Canadian mortality and fertility regime obtained in 1981 , female cohorts will be devoting relatively minor parts of the total volume of life years to parenting - either because many will not be parents at all or because those who are parents will be parents for relatively short periods and to few children.

Whether the release from the traditionally lengthy involvement in parenting and childrearing is viewed as burden or as freedom, whether welcomed as liberation or dreaded as encumbrance, it is necessary to view the compacting and contraction of parenthood as fact. Very much of future social, economic and political organization and activity depends upon the directions to which women will turn and the purposes to which they will mobilize their activity, attention, aspirations and commitment.

Analyses and estimates of kin availability and joint survival are important for alerting us to, and measuring the relative weights of, changes of various types and magnitudes in the mortality and fertility regimes upon the size and composition of kinship networks. Moreover, they can be combined to study the changes in kinship networks at successive ages through the life course: the size and the composition of an individual's network of kin changes as he himself ages and passes through life. For example, as Keyfitz has shown for Canadian fertility and mortality conditions of 1971 and 1981, while probabilities of having living parents and living grandparents decline through the life course, expected numbers of live siblings rise to a peak at about age 25 and decline thereafter; expected numbers of live children rise to a peak at about age 45 and decline thereafter; and expected numbers of cousins also peak at about age 25 , all in consequence of the regime of mortality and fertility (Keyfitz, 1986).

It is hard to exaggerate the importance of the kinship network and its changes in the life course of the individual. It is a "convoy of social support" (Kahn, 
1979), on the one hand, and a collection of obligations and claims on his or her own energies and resources, on the other hand. But the "availability of kin" as directly determined by the demographic regime is only one dimension of the relationship between kin networks and life course activity and transitions of individuals. It is the nature of the relations of mutual support, dependency, obligations and entitlements in the kinship network that bears most heavily on individual life course activity and transitions. These support and obligation relationships are, in turn, conditioned on the one hand by size and composition of the kinship networks at any stage or any point in time, as well as by longevity and joint survival horizons and by parenting norms and horizons; and, on the other hand, by existing alternative "extra-kin network" support, dependency, obligations or entitlements.

An important theme in historical studies of the family is the substitution of market and of public or state loci of support, dependency, obligations and entitlements for those traditionally located in the family and in kin networks. Such substitution also bears importantly upon the structure and timetables of the individual life course (Hareven, 1982a; Katz, 1982; Modell et al., 1976). These, in turn, are viewed partially as outcomes of the demographic transitions themselves and partially as outcomes of the industrialization, modernization, migration, urbanization and differentiation of family from employment and productive activity over time.

Unfortunately, broadly-based (as distinct, say, from case study) information even on the "availability of kin," much less on the characteristics of kin network members and on the ways in which kin are supportive and provide resources to - or, conversely, in which kin place demands upon and drain resources from - the individual, is very meager. Yet a central hypothesis of this work is that the pattern of dependency, obligations, and entitlements inside and outside the kinship network is a major determinant of the timing and directions of major life course transitions ... whether schooling, household formation, marriage or other sexual union formation or dissolution, seeking employment or withdrawing from employment, and - possibly - health and morbidity transitions. Exploration and testing of this hypothesis is the major challenge posed here.

The hypothesis is by no means a novel one, though perhaps here it is formulated more generally than usual. Sibship size and birth order have been found to have statistically significant effects on various facets of status attainment and socioeconomic achievement (Blau and Duncan, 1967; Boyd, 1985; Boyd et al., 1980; Duncan et al., 1972; Featherman and Hauser, 1978; Hauser and Featherman, 1977; Hauser et al., 1982), though no exact mechanism nor dependency conditions beyond the presumption of availability of parental time and resources has been established. There are a prominent hypothesis and some 
suggestive findings relating earning capabilities of women to the propensities to divorce and separation. Indeed at least one study has suggested that income maintenance or provision schemes have the effect of allowing women otherwise entirely dependent on husbands to separate or divorce (Groeneveld et al., 1980; Tuma and Hannon, 1984: sections 6.2 and 7.2).

Studies in the American negative income tax experiment program have suggested that availability of extra-employment income entitlements bears on the propensity of youths and of adult men and women to remain in employment or to seek new employment after job terminations (McDonald and Stephenson, 1979; Robins et al., 1980; West, 1980). The very few studies of the timing of departure of youths or young adults from parental homes suggest the importance of either employment and self-support or sufficient parental support for establishment of separate dwelling arrangements as factors in the early (pre-marriage) departure from parental homes (Goldscheider and DaVanzo, 1985; LeBourdais and Goldscheider, 1986; Young, 1974, 1975). Kobrin (1976), Pampel (1983), Sweet and Bumpass (1984) and others have suggested that the great increase in single-person household formation and maintenance among elderly widows rests upon their liberation from financial dependency upon their children. Residential patterns of elderly are frequently found to be related to their independence or dependency in activities of daily life (ADL).

Finally, the analysis of Oppenheimer relates the entrance of women into the labour force to family life cycle-based income squeezes coincident with the possibility, from the point of view of age composition of family members, for women to seek extra-household employment (Oppenheimer, 1982). According to this analysis, individuals, couples, and families experience relative deprivation and economic stress in relation to the actual or anticipated burdens and costs of marriage and setting up a household or in relation to child dependency. The latter, especially, varies and changes during the life cycle and in accordance with the number and ages of children. The responses to life-cycle squeezes and dependency which Oppenheimer analyzes include postponement of marriage, the timing of childbearing and family limitation, and especially, the labour force participation of wives. We return to this hypothesis in the companion paper, Part II (Matras, 1990).

\section{Concluding Remarks}

Declining mortality and fertility have led to population aging and, not less important, to restructuring of the individual life course and family cycle. Increased longevity has been followed by diminished parenting, family size, 
sibships and child dependency; by lengthened pre-childbearing and "empty nest" periods for intact couples; but also by extended parental survival and dependency. We conjecture and hypothesize that the frequencies, directions and timing of life course and family cycle transitions such as school leaving, leaving the parental home, entering employment, marriage, childbearing, household formation, migration, job mobility, retirement and the life are closely related to the constellation of family dependencies and obligations as well as to intra- and extra-family income and service entitlements (Hareven, 1982b).

While "dependency ratios" - the ratios of pre-working-age and post-working-age population to working-age population - for entire populations and societies are familiar measures in demography and in economics (see, for example, Habib, 1985; Hauser, 1979; Matras, 1973, 1977), they may be said to measure a type of "macro-dependency." Measures of the intra-family "microdependency" which we wish to study have not yet been well-developed or standardized (Finch, 1987; Sorensen and McLanahan, forthcoming). Yet the variations in such intra-family micro-dependency induced by changes and variations in demographic trends and behaviour are a most important link between population trends and structure, individual life course and family cycle, and the social organizational settings and arrangements in which life course and family cycle are played out and, accordingly, call for more systematic attention and research.

1. The probability of being a parent at that age is taken as the probability of having had at least one birth over the past 15 years, that is, at ages $(x-14)$ to $(x)$. It is estimated here using the age-specific fertility rates, $f(x)$, of Table 2 as

$$
\begin{aligned}
\operatorname{Par}(x) & =\text { Prob. [at least one birth at ages }(x-14) \text { through }(x)] \\
& =1-\text { Prob. [no births at ages }(x-14) \text { through }(x)] \\
& =1-\underset{x-14}{-x}(1-f(t))
\end{aligned}
$$

Thus the assumption is that the women "parent" their children at birth and continue to "parent" them for 15 years thereafter if they survive. 


\section{Judah Matras}

For each age interval, $x$ to $x+4$, the caluculation uses:

$$
\left.\operatorname{Par}(x)=1-\left[1-f_{(x-15-x-1 H)}\right)^{2.5}\left(1-f_{(x-30-x-6)}\right)^{5}\left(1-f_{(x-5-x-x-1)}\right)^{5}\left(1-f_{(x-x+4)}\right)^{2.5}\right]
$$

and the estimated number of female life yers in parenting in each age interval, $x$ to $x+4$, say $L p(x)$, is

$$
L p(x)=L(x) \operatorname{Par}(x)
$$

where the $L(x)$ are the stationary populations or numbers of life years lived by females in each age interval, $x$ to $x+4$, taken from the Appendix Table A. Analagous estimates could, of course, be derived from men's life years in parenting using male age-specific birth rates.

\section{References}

Blau,P.M. and O.D. Duncan. 1967. The American Occupational Structure.New York: Wiley.

Bongaarts, J., T. Burch and E. Wachter (eds.). 1987. Family Demography: Methods and Their Applications. Oxford: Clarendon Press.

Boyd, M. 1985. Immigration and occupational attainment in Canada. In M. Boyd et al. (eds.), Ascription and Achievement: Studies in Mobility and Status Attainment in Canada. Ottawa: Carleton University Press.

Boyd, M., D.L. Featherman and J. Matras. 1980. Status attainment of immigrant and immigrant origin groups in the United States, Canada and Israel. Comparative Studies in Sociology 3.

Davis, K. 1984. Wives and work: The sex role revolution and its consequences. Population and Development Review 10:397-417.

Davis, K. and P. van den Oever. 1982. Demographic foundations of new sex roles. Population and Development Review 8:495-511.

Duncan, O.D., D.L. Featherman and B. Duncan. 1972. Socioeconomic Background and Achievement. New York: Seminar Press.

Elder, G.H., Jr. 1975. Age differentiation and the life course. Annual Review of Sociology 1:165-190.

Featherman, D.L. 1985. Life-span perspectives in social science research. In P.B. Baltes and O.G. Brim, Jr. (eds.), Life-Span Development and Behaviour, Vol. 5. New York: Academic Press. 
Featherman, D.L. and R.M. Hauser. 1978. Opportunity and Change. New York: Academic Press.

Feichtinger, G. 1987. The statistical measurement of the family life cycle. In J. Bongaarts, T. Burch and E. Wachtel (eds.), Family Demography: Methods and Their Application. Oxford: Clarendon Press.

Finch, J. 1987. Family obligations and the life course. In A. Bryman et al. (eds.), Rethinking the Life Cycle. London: Macmillan Press Ltd.

Goldscheider, F.K. and J. DaVanzo. 1986. Semiautonomy and leaving home in early adulthood. Social Forces 65(1): 187 - 201

Goodman, L., N. Keyfitz and T.W. Pullum. 1974. Family formation and the frequency of various kinship relationships. Theoretical Population Biology 5:1-27.

Groeneveld, L.P., N.B. Tuma and M.T. Hannan. 1980. The effect of negative income tax programs on marital dissolution. Journal of Human Resources 15:654-74.

Hagestad, G.O. 1986. The aging society as a context for family life. Proceedings of the American Academy of Arts and Sciences 115:119-139.

Hareven, T.H. 1982a. The life course and aging in historical perspective. In T.R. Hareven and K.J. Adams (eds.), Aging and Life Course Transitions: An Interdisciplinary Perspective. New York: Guildford Press.

. 1982b. Family Time and Industrial Time: The Relationship Between Family and Work in a New England Industrial Community. New York: Cambridge University Press.

Hauser, P.M. 1979. Introduction and Overview. In P.M. Hauser (ed.), World Population and Development. Challenges and Prospects. Syracuse: Syracuse University Press.

Hauser, R.M. and D.L. Featherman. 1977. The Process of Stratification: Trends and Analysis. New York: Academic Press.

Hauser, R.M., W.H. Sewell and B.R. Clarridge. 1982. The influence of family structure on socioeconomic achievement: A progress report. CDE Working Paper 82-59. Madison: Center for Demography and Ecology, University of Wisconsin.

Kahn, R.L. 1979. Aging and social support. In M.W. Riley (ed.), Aging from Birth to Death. Interdisciplinary Perspectives. AAAS Selected Symposium 30. Boulder: Westview Press. 


\section{Judah Matras}

Katz, M.B. 1982. Families and early industrialization: Cycle, structure, and economy. In M.W. Riley, R.P. Abeles and M.S. Teitelbaum (eds.), Aging from Birth to Death. Vol. 2: Sociotemporal Perspectives. AAAS Selected Symposium. Boulder: Westview Press.

Keyfitz, N. 1985. Applied Mathematical Demography. 2nd ed. New York: John Wiley.

1986. Canadian kinship patterns based on 1971 and 1981 data. Canadian Studies in Population 13(2):123-150.

Kobrin, F.L. 1976. The fall in household size and the rise of the primary individual in the United States. Demography 13: 127-138.

1980. Children and the household economy: Ethnic differences in leaving home. Paper presented at Social Science History Asosociation Meeting, Rochester, N.Y., November.

LeBourdais, F. and F.K. Goldscheider. 1986. The falling age at leaving home, 1920-1979. Sociology and Social Research 70:143-5.

Lehrer, E. and M. Nerlove. 1986. Female labor force and fertility in the United States. Annual Review of Sociology 12:181-202.

Matras, J. 1973. Populations and Societies. Englewood Cliffs: Prentice-Hall.

. 1977. Introduction to Population: A Sociological Approach. Englewood Cliffs: Prentice-Hall.

1990. Demographic trends, life course, and family cycle - the Canadian example: Part II. Employment, parenting, and their alternatives. Canadian Studies in Population 16(2): forthcoming.

Mayer, K.-U. and W. Muller. 1987. The state and the structure of the life course. In A.B. Sorensen, F.E. Weinert and L. Sherrod (eds.), Human Development and the Life Course: Multidisciplinary Perspectives. Hillsdale, New Jersey: Erlbaum.

McDonald, J. and Stephenson, S.P., Jr. 1979. The effect of income maintenance on the school enrollment and labour supply decisions of teenagers. Journal of Human Resources 15:488-506.

Modell, J, F. Furstenberg, Jr. and T. Hershberg. 1976. Social change and transitions to adulthood in historical perspective. Journal of Family History 1:17-31.

Nagnur, D. 1986. Longevity and Historical Life Tables. 1921-1981 (Abridged). Canada and the Provinces. Catalogue 89-506. Ottawa: Statistics Canada. 
Oppenheimer, V.K. 1982. Work and the Family: A Study in Social Demography. New York: Academic Press.

Pampel, F. 1983. Changes in propensity to live alone. Demography 20:433-48.

Robins, P.K., N.B. Tuma and K.E. Yaeger. 1980. Effects of SIME/DIM on change in employment status. Journal of Human Resources 15:544-73.

Rossi, P. 1955. Why Families Move. New York: Free Press.

Shmueli, A. 1985. The Demography of Kinship in Israel, 1960-80. Discussion Paper 116-85. Jerusalem: Brookdale Institute. (In Hebrew)

Sorensen, A. and S. McLanahan. Forthcoming. Married women's economic dependency: 1940-1980.

Sweet, J.A. 1979a. Changes in the allocation of time of young women among schooling, marriage, work and childrearing: 1960-76. CDE Working Paper 79-15. Madison: Center for Demography and Ecology, University of Wisconsin.

$1979 \mathrm{~b}$. Changes in the allocation of time of young men among schooling, marriage, work and childrearing: 1960-76. CDE Working Paper 79-28. Madison: Center for Demography and Ecology, University of Wisconsin.

. 1979c. Ethnic differences in the allocation of the young adult years: Comparisons among white, black, and Mexican-American men and women. CDE Working Paper 79-31. Madison: Center for Demography and Ecology, University of Wisconsin.

Sweet J. A. and L.L. Bumpass. 1984. Living arrangements of the elderly in the United States. CDE Working Paper 84-11. Madison: Center for Demography and Ecology, University of Wisconsin.

Tuma, N.B. and M.T. Hannan. 1984. Social Dynamics: Models and Methods. New York: Academic Press.

Watkins, S.C., J.A. Menken and J. Bongaarts. 1987. Demographic foundations of family change. American Sociological Review 52:346-358.

West, R.W. 1980. The effects of SIME/DIME on the labor supply of young non-heads of households. Journal of Human Resources 15:574-96.

Young, C.M. 1974. Ages, reasons, and sex differences for children leaving home. Observations from survey data for Australia. Journal of Marriage and the Family 36:769-78.

.1975. Factors associated with timing and duration of the leaving home stage of the family life. Population Studies 29:61-73. 
Received December, 1987; revised September, 1988.

APPENDIX TABLE A. LIFE TABLE STATIONARY POPULATIONS (Lx) BY SEX AND AGE, CANADA: 1920-22, 1950-52, AND 1980-82

\begin{tabular}{|c|c|c|c|c|c|c|}
\hline \multirow[t]{2}{*}{ AGE } & \multicolumn{2}{|c|}{ MALES } & \multirow[b]{2}{*}{$1980-82$} & \multicolumn{2}{|c|}{ FEMALES } & \multirow[b]{2}{*}{$1980-82$} \\
\hline & $1920-22$ & $1950-52$ & & $1920-22$ & $1950-52$ & \\
\hline Total & 5884297 & 6640474 & 7187867 & 6060369 & 7090403 & 7905888 \\
\hline $\begin{array}{l}<1 \\
1-5 \\
5-10 \\
10-15 \\
15-20\end{array}$ & $\begin{array}{r}93642 \\
355786 \\
437484 \\
431181 \\
426550\end{array}$ & $\begin{array}{l}96853 \\
380884 \\
4738673 \\
471796 \\
469277\end{array}$ & $\begin{array}{r}99219 \\
395046 \\
493057 \\
492260 \\
490237\end{array}$ & $\begin{array}{r}95029 \\
363951 \\
448384 \\
443286 \\
438358\end{array}$ & $\begin{array}{r}97502 \\
384673 \\
479128 \\
477691 \\
476163\end{array}$ & $\begin{array}{r}99395 \\
396171 \\
494668 \\
494120 \\
493283\end{array}$ \\
\hline $\begin{array}{l}20-25 \\
25-30 \\
30-35 \\
35-40 \\
40-45 \\
45-50 \\
50-55 \\
55-60\end{array}$ & $\begin{array}{l}419355 \\
411352 \\
403587 \\
395307 \\
385378 \\
373208 \\
357719 \\
335826\end{array}$ & $\begin{array}{l}465445 \\
461247 \\
456966 \\
451834 \\
444656 \\
433456 \\
415880 \\
389475\end{array}$ & $\begin{array}{l}486637 \\
483022 \\
479809 \\
476170 \\
470962 \\
462559 \\
448753 \\
426923\end{array}$ & $\begin{array}{l}431338 \\
422852 \\
413778 \\
403470 \\
392058 \\
379327 \\
363231 \\
342321\end{array}$ & $\begin{array}{l}474081 \\
471631 \\
468676 \\
464647 \\
458867 \\
450338 \\
438186 \\
420718\end{array}$ & $\begin{array}{l}492141 \\
490922 \\
489513 \\
487557 \\
484430 \\
479499 \\
471735 \\
459787\end{array}$ \\
\hline $\begin{array}{l}60-65 \\
65-70 \\
70-75\end{array}$ & $\begin{array}{l}305845 \\
265881 \\
211245\end{array}$ & $\begin{array}{l}352019 \\
303399 \\
243457\end{array}$ & $\begin{array}{l}394261 \\
347927 \\
286927\end{array}$ & $\begin{array}{l}314989 \\
276243 \\
222880\end{array}$ & $\begin{array}{l}394647 \\
356945 \\
303319\end{array}$ & $\begin{array}{l}442037 \\
415717 \\
377110\end{array}$ \\
\hline $\begin{array}{l}75-80 \\
80-85 \\
85-90 \\
90+\end{array}$ & $\begin{array}{r}145935 \\
83022 \\
35237 \\
10057\end{array}$ & $\begin{array}{r}172490 \\
100093 \\
42967 \\
14413\end{array}$ & $\begin{array}{r}213787 \\
136606 \\
70137 \\
33568\end{array}$ & $\begin{array}{r}158584 \\
93990 \\
42192 \\
14108\end{array}$ & $\begin{array}{r}230391 \\
145544 \\
69844 \\
27412\end{array}$ & $\begin{array}{l}322001 \\
246862 \\
159068 \\
109872\end{array}$ \\
\hline
\end{tabular}

Source: D.Nagnur, 1986. Longevity and Historical Life Tables 1921-1981 (Abridged) Canada and the Provinces. Ottawa: statistics Canada. Catalogue 89-506. 